\title{
Negative childhood experiences and health inequalities among adults over 45: Evidence from China
}

\section{Yiwei Liu}

Central University of Finance and Economics

Li Diao ( $\nabla$ diaoli0322@163.com )

Wuhan University https://orcid.org/0000-0002-2844-512X

Ling Xu

University of Texas at Arlington

Research article

Keywords: Concentration index, Health inequality, Negative childhood experience, Self-rated health, China

Posted Date: December 13th, 2019

DOl: https://doi.org/10.21203/rs.2.18831/v1

License: (1) This work is licensed under a Creative Commons Attribution 4.0 International License.

Read Full License

Version of Record: A version of this preprint was published at Infant and Child Development on March 11th, 2021. See the published version at https://doi.org/10.1002/icd.2224. 


\section{Negative childhood experiences and health inequalities among adults over 45: Evidence from China}

Yiwei Liu ${ }^{1}$, Li Diao ${ }^{2, *}$ and Ling $\mathrm{Xu}^{3}$

Author information

1.School of government, Central University of Finance and Economics, 39 South College Road, Haidian District, Beijing 100081, China. Email: liuyiweioffice@163.com

2.Center for Social Security Studies, Wuhan University, 16 Bayi Road, Wuchang District, Wuhan 430072, China. Email: diaoli0322@163.com

3. School of Social Work, University of Texas at Arlington. 211 S. Cooper Street, Arlington, TX 76091. Email: lingxu@uta.edu

* Correspondence: diaoli0322@,163.com Tel: +86 13277038851 


\begin{abstract}
Background: Growing health inequalities have become an important challenge for Chinese society. This study analyses the impact of negative childhood experiences on health among Chinese adults over 45 .
\end{abstract}

Methods: This study utilized data from the 2014 Life Course Survey under the China Health and Retirement Longitudinal Study, with a total sample of 5,842 adults over the age of 45. This paper used a linear regression model to analyse the factors affecting the self-rated health of respondents. The concentration index was then used to measure the degree of health inequality, and finally, we decomposed the concentration index.

Results: The regression results showed that negative childhood experiences had a significant negative impact on the health of adults over $45(\beta=-0.021, p<.000)$. The concentration index decomposition found that negative childhood experiences was associated with more health inequalities. The elasticity coefficient for negative childhood experiences was -0.119 , the concentration index of negative childhood experiences was -0.019 , and the contribution to health inequalities was $12.86 \%$. The mechanism test and analysis found that negative childhood experiences have a greater negative impact on the health of the low-income group than on that of the high-income group. In fact, negative childhood experiences have reduced the socioeconomic status of respondents, leading to a decline in healthcare utilization, which has increased health inequalities in China.

Conclusion: This study found that negative childhood experiences was associated with health inequalities among adults over 45 in China. To improve the health of residents 
and to reduce health inequalities, more help and health interventions should be offered to groups with negative childhood experiences.

Keywords: Concentration index, Health inequality, Negative childhood experience, Self-rated health, China

\section{Background}

In recent years, with the improvement in living conditions and medical treatments, the general level of individual health in China has greatly improved, but health inequalities among different individuals and groups are continuing to grow [1]. The expansion of health inequalities will not only damage demographic sustainability but also have a negative impact on social stability and will ultimately affect the overall social welfare negatively.

An increasing number of scholars believe that only by grasping the timeliness of events is it possible to recognize their nature [2]. Usingthe life course theory, scholars have proven that early childhood experiences, such as war [3], famine [4] and influenza [5], can have significant impacts on health, education, and occupation in adulthood [6]. Although academia has paid attention to the impact of childhood experiences on health, the existing literature has not studied the impact of childhood experiences on health inequalities. Some scholars note that the study of health inequalities should not only focus on current socioeconomic factors but also consider factors in the early years [7]. Since the founding of the People's Republic of China in 1949, China has undergone many important transition periods, such as the Great Famine from 1959 to 1961, the Cultural Revolution from 1966 to 1976, and the Reform and Opening-up beginning in 
1978. These periods not only had a significant impact on society but also had a significant impact on Chinese families. Most Chinese middle-aged and older adults were born from the 1940s to the 1960s, and some suffered from famine, neglect and even abuse and bullying by neighbours and family members in their childhood, which may cause health issues in later life and lead to the aggravation of health inequalities in the middle-aged and elderly adult population in China. However, no studies have examined how early negative childhood experience impacted the health inequalities later on, and through what mechanism such influences occurred. Using data from the China Health and Retirement Longitudinal Study (CHARLS) Life Course Survey in 2014, this study aimed to address such research gaps.

\section{Theoretical Analysis and Literature Review}

Research on health inequalities focused on how to measure health inequalities and the causes of health inequalities. There are many ways to measure health inequalities, but the most common is the concentration index. Because health inequalities can be calculated, further mathematical methods can be used to study the causes of health inequalities $[9,10]$. Moreover, the factors affecting health inequalities can be divided into two categories. The first category is social policy, such as social medical insurance policy and social welfare policy $[11,12]$; the other category includes individual socioeconomic characteristics, and income is the factor that draws the most attention. The general conclusion of this research is that high-income groups have better health status and low-income groups have worse health status, leading to health inequalities among the "pro-rich" in many countries [13-15].Previous literature has focused on what 
factors affect health inequalities, and can provide a reference for seeking controlled variables in this paper, but the above literature ignored the impact of negative childhood experiences on residents' health and health inequalities.

Since the 1960s, the life course theory has been applied in social science research. This theory focuses on the impact of events in the full life course on individual development [16]. In recent decades, the life course theory has gradually become an important analytical theory for studying health, health behaviour and death. In the field of health research, the life course theory holds that childhood is the foundation for the development of people's entire life cycle; in other words, the events experienced in childhood are the "starting point" and basis of many diseases of adulthood [17]. However, Ben-Shlomo and Kuh [18] found that socioeconomic status in adulthood can compensate for this negative effect. Thus, this section mainly discusses health impacts from two perspectives: negative childhood experiences and socioeconomic status in adulthood based on this life course theory.

Extensive studies have been conducted to test the relationship between negative childhood experiences and health, and the results were mixed. On the one hand, some researchers have found that negative childhood experiences may lead to health issues in adulthood. Acquired diseases such as heart disease, diabetes, and high blood pressure may be attributed to hypogenesis [19] and malnutrition [20,21] during the foetal period or during childhood experiences of famine [22]. With randomized experiments in developing countries, some economists have even discovered that negative childhood experiences have led to cognitive dysfunction, which in turn has brought about health 
issues in adulthood [23-25]. In addition, some studies found that famine or malnutrition early in life had no significant effect on health [26,27]. However, on the other hands, some researchers have showed opposite results. For example, some scholars have analysed government-implemented child policies from the opposite perspective and their impact on health and income in adulthood, such as the malaria eradication campaign in South America [28] and the US food stamp programme [29]. They found that improvements in nutrition in childhood could help to improve health and income in adulthood.

Regarding research on socioeconomic status and health, some literature has found that improved socioeconomic status in adulthood can have a protective effect, which can compensate for the negative effect on health brought by negative childhood experiences [30]. However, some scholars found that negative experiences in the early years were highly related to socioeconomic status in adulthood [1,31]. Montez and Hayward [32] found that negative childhood experiences increased the incidence of disability and mortality in adulthood, which leaded to low socioeconomic status. Shi [7] found that childhood experiences of poverty and abuse not only leaded to health issues but also declines in socioeconomic status and unhealthy lifestyles in adulthood.

Regarding such research in China, many scholars paid attention to famine of "threeyear hard period" when the Chinese suffered through a very severe famine from 1959 to 1961 and people born in this period of time generally have experiences with "starving" and "fleeing". Studies found that individuals born or growing up in the "three-year hard period" generally have shorter heights, worse health and lower income in adulthood 
[27].

Though existing health research indicates growing interest in childhood experiences, the following research gaps still exist: 1) existing studies focus on the impact of negative childhood experiences on health, but none of them have studied its impact on health inequalities; and 2) most of the current research focuses on single experience, and overestimates its impact on health, but ignores the cumulative effects of different experiences on health or even health inequalities [33]. This paper will fill in such research gaps, and enrich existing research by contributing literature on health inequalities in the following aspects. First, CHARLS Life Course Survey study is used to provide retrospective data on childhood experiences from a large number of respondents. The survey comprises individuals over 45 years old, and most of the respondents experienced negative events, such as famine in their early years. Second, we construct an indicator that can measure the extent of an individual's suffering from negative childhood experiences. This indicator aggregates multiple types of negative experiences and can help capture the cumulative stress of multiple traumas [34]. Third, we focus on the mechanism of the impact of negative childhood experiences on health inequalities, thus providing references for health inequality studies.

\section{Methods}

\section{Data and sampling}

This study utilized data from the China Health and Retirement Longitudinal Survey (CHARLS) Life Course Survey, which was conducted by the National School of Development, Institute of Social Science Survey and Communist Youth League at 
Peking University in 2014. The CHARLS is currently the only nationwide household survey in China targeting middle-aged and older adults. The questionnaire included items on respondents' demographic background, occupation, retirement and pension status, health status and medical service utilization, household income, expenditure and assets, and early life experience.

The CHARLS conducted the baseline survey in 2011 and a follow-up survey in 2013. A total of 150 counties and 450 communities (villages) in 28 provinces (autonomous regions and municipalities) were included in the 2013 CHARLS. The entire survey sample contains more than 10,000 households and nearly 20,000 individuals. In 2014, the CHARLS further conducted a life course survey of respondents, which is a special survey to record the life experiences of CHARLS respondents since their birth, including migration and childhood socioeconomic conditions. A life course survey can help to fully clarify the influencing factors of health status among middle-aged and older adults from the perspective of the entire life course. After deleting those who were younger than 45 , or those with missing data, the final sample size was 5, 842 participants.

\section{Dependent variable}

Self-rated health (SRH) was applied to assess the health level of adults over 45 in this paper. SRH has several outstanding advantages. First, unlike single indicators such as prevalence and disability rate, $\mathrm{SRH}$ is a comprehensive indicator that can fully reflect the individual's health status. Second, although SRH is subjective and has certain measurement errors, many studies have shown that SRH can effectively predict 
mortality and functional damage $[35,36]$. Third, SRH is simple and easy to obtain. In this study, SRH is coded as "very poor, poor, fair, good, very good", respectively. $5.23 \%, 20.11 \%, 52.72 \%, 13.43 \%$ and $8.51 \%$ of the participants reported their SRH as "very poor, poor, fair, good, very good", respectively.

\section{Independent variable}

The independent variable is negative childhood experiences. Drawing from the selection of indicators from previous studies [38], we focus on exogenous and irreversible experiences. The independent variable in the present study were: parents' issues, violence, and famine and fleeing. Parents' issues were measured by these questions: "Did your parents have a long time be sick on bed when you were young?", "Did your parents have abnormality of mind when you were young?", "Did your parents often quarrel?", "Were your biological parents divorced?";Violence is determined by these questions: "When you were a child, had you often picked on or bullied by kids in your neighbourhood or your classmates?", "When you were growing up, did your female guardian often hit you?";Famine and fleeing were measured by this question: "When you were a child before age 17, was there ever a time when your family (including your grandparents, parents, siblings, children and so on) did not have enough food to eat and even moved away from the famine-stricken area?".

For each of the questions above, "yes" indicated "1" and "no" was set to "0". Sum scores were calculated for the above questions to measure the numbers of negative childhood experiences to indicate the extent of an individual's suffering from negative 
childhood experiences. The sum scores ranged from 0 to 7 , and $12.79 \%$ of the participants had never experienced negative events in their childhood.

Table 1 Descriptive statistics of the number of negative childhood experiences

\begin{tabular}{l|llllllll}
\hline $\begin{array}{l}\text { Number of negative } \\
\text { childhood experiences }\end{array}$ & 0 & 1 & 2 & 3 & 4 & 5 & 6 & 7 \\
\hline $\begin{array}{l}\text { Sample size } \\
\text { Percentage }\end{array}$ & 758 & 1,992 & 1,885 & 880 & 302 & 92 & 13 & 4 \\
$\begin{array}{l}\text { Cumulative } \\
\text { percentage }\end{array}$ & $12.79 \%$ & $33.61 \%$ & $31.81 \%$ & $14.85 \%$ & $5.10 \%$ & $1.55 \%$ & $0.22 \%$ & $0.07 \%$ \\
\hline
\end{tabular}

\section{Controlled variables}

Controlled variables were classified into three categories. The first category describes the social demographic characteristics of individuals, including age (in years), gender $($ male $=1$, female $=0)$, education level (in years; illiterate $=0$, primary school $=6$, middle school $=9$, high school $=12$, university $=16$, , hukou (urban area $=1$, rural area $=0$ ), marital status (married $=1$, unmarried $=0$ ), family size (number of family members living together), and household per capita income (household income/family population).

The second category of control variables included individual's living habits. Among the factors affecting public health, living habits are recognized as the primary factor that contributes most to an individual's health compared to socioeconomic and environmental factors. Engel [39] concluded that 50\% of diseases were related to living habits. This article used exercise, smoking and drinking as proxy variables for living habits. If the respondent reported that they had regular exercises for at least one year, we assigned a value of 1 to the variable; otherwise, we assigned a value of 0 . If the respondent has a history of smoking cigarettes and drinking alcohol, we assign a value 
of 1 to the variable; otherwise, we assign a value of 0 .

The third category of control variable included family factors. Studies have shown that parents' genetics, health and preferences can affect both experiences in the early years and current health [40]. Because there were no information of genetic inheritance and personality in the CHARLS Life Course Survey data, we use characteristics of the respondents' native family in their childhood as proxy variables, including both father and mother's education levels (in years, illiterate $=0$, primary $=6$, secondary $=9$, high school $=12$, university $=16$ ), parent's family origin (poor peasant $=1$, otherwise $=0$ ), care received from parents (yes $=1$, otherwise $=0$ ), and family economic status in respondents' childhood $($ good $=1$, bad $=0$ ). Specific variable definitions and basic information are shown in Table 2.

Table 2 Descriptive statistics of controlled variables

\begin{tabular}{|c|c|c|c|}
\hline \multirow[t]{2}{*}{ Variables } & & Variable definitions & Population $(\mathrm{N}=$ \\
\hline & & & $\begin{array}{l}\text { Mean or } \\
\text { percentage }\end{array}$ \\
\hline \multirow{7}{*}{$\begin{array}{l}\text { Variables of social } \\
\text { demographic characteristics }\end{array}$} & Age & $\begin{array}{l}\text { Continuous variable: age of the } \\
\text { participant }\end{array}$ & Mean $=61.439$ \\
\hline & Gender & $\begin{array}{l}\text { Dummy variable: } \text { male }=1 \text {, } \\
\text { female }=0\end{array}$ & $\begin{array}{l}1=50.1 \% \\
0=49.9 \%\end{array}$ \\
\hline & Hukou & $\begin{array}{l}\text { Dummy variable: } \text { urban area }=1 \text {, } \\
\text { rural area }=0\end{array}$ & $\begin{array}{l}1=20.35 \% \\
0=79.35 \%\end{array}$ \\
\hline & Education level & $\begin{array}{l}\text { Continuous variable: } \\
\text { respondents' schooling years }\end{array}$ & Mean $=4.993$ \\
\hline & Marital status & $\begin{array}{l}\text { Dummy variable: } \text { married }=1 \text {, } \\
\text { other }=0\end{array}$ & $\begin{array}{l}1=73.8 \% \\
0=26.2 \%\end{array}$ \\
\hline & $\begin{array}{l}\text { Logarithm of per capita } \\
\text { household income }\end{array}$ & Continuous variable & Mean $=6.983$ \\
\hline & Family size & $\begin{array}{l}\text { Continuous variable: } \\
\text { respondents' family population }\end{array}$ & Mean $=3.096$ \\
\hline Variables of living habits & Exercise for at least 1 & Dummy variable: yes $=1$, no $=0$ & $1=16.1 \%$, \\
\hline
\end{tabular}




$\begin{array}{lll}\text { year } & & 0=83.9 \% \\ \text { Smoking cigarettes } & \text { Dummy variable: yes=1, no=0 } & 1=33.3 \%, \\ \text { Drinking alcohol } & \text { Dummy variable: yes=1, no=0 } & 0=66.7 \% \\ & & 1=50.1 \%, \\ \text { Mother's education } & \text { Continuous variable: } & 0=49.9 \% \\ \text { level } & \text { Respondent's mother's schooling } & \\ & \text { years } & \\ \text { Father's education level } & \text { Continuous variable: } & \text { Mean }=2.813 \\ & \text { Respondent's father's schooling } & \\ & \text { years } & \\ \text { Father's family origin } & \text { Dummy variable: poor } & 1=66.5 \%, \\ & \text { peasant=1, otherwise=0 } & 0=33.5 \% \\ \text { Mother's family origin } & \text { Dummy variable: poor } & 1=70.7 \%, \\ & \text { peasant=1, otherwise }=0 & 0=29.3 \% \\ \text { Care received from } & \text { Dummy variable: yes=1, no=0 } & 1=77.6 \%, \\ \text { parents } & & 0=22.4 \% \\ & & 1=61.39 \%, \\ & & 0=38.61 \%\end{array}$

Variables of family
characteristics in childhood

Statistical analysis

Depending on the study purpose, previous studies have proposed two measures of inequality in health, namely, pure inequalities and socioeconomic inequalities. This article uses socioeconomic inequalities in health, specifically, inequalities in health related to income. The most common measure of health inequalities related to income is the health concentration index and its decomposition, where the concentration index is based on a concentration curve.

The health concentration curve contains two key elements: one is the health indication, and the other is socioeconomic status, which must be a continuous variable and was characterized by income in this study. The health concentration curve is combined, given both the cumulative population ranked by income (horizontal axis) and their corresponding health status (vertical axis). The concentration index is calculated based 
on the concentration curve, which is twice the area between the concentration curve and the fair line [13]. The mathematical expression for the concentration index is as follows:

$C=1-2 \int_{0}^{1} L_{h}(p) d p$

where $\mathrm{C}$ is the concentration index and $\mathrm{L}$ is the concentration curve. When the concentration curve coincides with the fair line, $\mathrm{C}$ is equal to 0 ; when the concentration curve is above the fair line, $\mathrm{C}$ is negative; and when the concentration curve is below the fair line, $\mathrm{C}$ is positive.

The concentration curve and concentration index can only indicate the existence and extent of inequality. To investigate which factors contribute to health inequality, the CI decomposition method is needed. Through CI decomposition, the contribution of each influencing factor can be decomposed. This paper used the Wagstaff linear method, the basic idea of which is similar to that of linear regression, which decomposes CI into parts that can be interpreted by observable variables and parts that cannot be explained by data (similar to the residuals in the regression).

Assuming the health indicator is $y$, the health influencing factors are ${ }^{x_{k}}$, and the linear regression equation is established as follows:

$y_{i}=\alpha+\sum_{k} \beta_{k} x_{k}+\varepsilon_{i}$

where $\beta_{k}$ is the coefficient and $\varepsilon_{i}$ is the residual. Assuming that the coefficient vector $\beta_{k}$ of each observation is the same, the difference in health comes from influencing factor $x_{k}$. The concentration index can be expressed as follows: 
$C I=\sum_{k}\left(\beta_{k} \overline{x_{k}} / v\right) C_{k}+G C_{\varepsilon} / v$

where $v$ is the mean of $y, \overline{x_{k}}$ is the mean of $x_{k}, C_{k}$ is CI of $x_{k}$, and $G C_{\varepsilon}$ is the $\mathrm{CI}$ of residual ${ }^{\varepsilon_{i}}$. CI is the weighted average of the CI of $k$ dependent variables, and the weight of variable ${ }^{x_{k}}$ is the elasticity of $y$ to ${ }^{x_{k}}$, which can be defined by the following equation: $\eta_{k}=\beta_{k} \overline{x_{k}} / v$.

\section{Results}

\section{Factors associated with self-rated health}

Table 3 reports the impact of negative childhood experiences on the SRH of adults over 45. Model 1 contains no controlled variables, and negative childhood experiences have a negative impact on SRH at the $1 \%$ significance level $(\beta=-0.0287, \mathrm{P}<0.001)$. Considering that other missing variables may affect the robustness of the regression results, we added variables for social demographics, living habits and family characteristics in order from Model 2 to Model 4, and statistically significant negative impacts were also shown in these models $(\mathrm{P}<0.001)$, guaranteeing the robustness of regression results.

Controlled variables also have an important impact on the SRH of adults over 45. First, among the variables of social demographic characteristics, age is negatively correlated with health status $(\beta=-0.00108, \mathrm{p}<0.001)$; males have a lower SRH $(\beta=-0.0385, \mathrm{P}<$ $0.001)$ than females. Moreover, respondents in rural areas have a higher SRH $(\beta=0.022$, $\mathrm{p}<0.001)$, unmarried respondents are healthier $(\beta=-0.0138, \mathrm{p}=0.051)$, and respondents with higher income have better health $(\beta=0.000719, \mathrm{p}<0.001)$. Second, in terms of variables for living habits, compared with respondents who do not exercise regularly, 
respondents who exercise regularly have better health $(\beta=0.0187, \mathrm{p}=0.023)$; Drinking alcohol has a significantly negative impact on health $(\beta=-0.0143, \mathrm{p}<0.001)$. Finally, among the variables for family characteristics, the higher the mother's education level is, the better the health status $(\beta=0.00258, \mathrm{p}=0.083)$. In addition, the higher the economic status of the childhood family was, the better the health status of adults over $45(\beta=0.0183, \mathrm{p}<0.001)$.

Table 3 The impact of negative childhood experiences on SRH

\begin{tabular}{|c|c|c|c|c|}
\hline Variable & (1) & (2) & (3) & (4) \\
\hline Negative childhood & $-0.0287 * * *$ & $-0.0254 * * *$ & $-0.0252 * * *$ & $-0.0210 * * *$ \\
\hline experiences & $(0.003)$ & $(0.003)$ & $(0.003)$ & $(0.003)$ \\
\hline \multirow{2}{*}{ Age } & & $-0.00114 * * *$ & $-0.00114 * * *$ & $-0.00108 * * *$ \\
\hline & & 0.000 & 0.000 & 0.000 \\
\hline \multirow{2}{*}{ Gender } & & $-0.0238 * * *$ & $-0.0350 * * *$ & $-0.0385 * * *$ \\
\hline & & $(0.006)$ & $(0.007)$ & $(0.007)$ \\
\hline \multirow{2}{*}{ Hukou } & & $0.0296^{* * *}$ & $0.0261 * * *$ & $0.0220 * * *$ \\
\hline & & $(0.008)$ & $(0.008)$ & $(0.008)$ \\
\hline \multirow{2}{*}{ Education level } & & $0.00155^{* *}$ & $0.00139 *$ & 0.000813 \\
\hline & & $(0.001)$ & $(0.001)$ & $(0.001)$ \\
\hline \multirow{2}{*}{ Marital status } & & $-0.0144 * *$ & $-0.0141 * *$ & $-0.0138 *$ \\
\hline & & $(0.007)$ & $(0.007)$ & $(0.007)$ \\
\hline \multirow{2}{*}{$\begin{array}{l}\text { Logarithm of per capita } \\
\text { household income }\end{array}$} & & $0.000869 * * *$ & $0.000832 * * *$ & $0.000719 * * *$ \\
\hline & & 0.000 & 0.000 & 0.000 \\
\hline \multirow{2}{*}{ Family size } & & -0.00216 & -0.00213 & -0.00203 \\
\hline & & $(0.002)$ & $(0.002)$ & $(0.002)$ \\
\hline \multirow{2}{*}{\multicolumn{2}{|c|}{ Exercise for at least 1 year }} & & $0.0197 * *$ & $0.0187 * *$ \\
\hline & & & $(0.008)$ & $(0.008)$ \\
\hline \multirow[t]{2}{*}{ Smoking cigarettes } & & & 0.000276 & 0.0000811 \\
\hline & & & $(0.003)$ & $(0.003)$ \\
\hline \multirow{2}{*}{ Drinking alcohol } & & & $-0.0143 * * *$ & $-0.0143 * * *$ \\
\hline & & & $(0.002)$ & $(0.002)$ \\
\hline \multirow{2}{*}{ Mother's education level } & & & & $0.00258 *$ \\
\hline & & & & $(0.001)$ \\
\hline \multirow{2}{*}{ Father's education level } & & & & 0.000564 \\
\hline & & & & $(0.001)$ \\
\hline Father's family origin & & & & 0.0043 \\
\hline
\end{tabular}


economic status

\begin{tabular}{llll} 
Constant & $0.335^{* * *}$ & $0.402 * * *$ & $0.428 * * *$ \\
& $(0.005)$ & $(0.030)$ & $(0.030)$ \\
Observations & 0.021 & 0.033 & 0.04 \\
\hline
\end{tabular}

(0.003)

P-values: $* * *<0.001, * *<0.05, *<0.1$

\section{Decomposition of health inequality}

On the basis of the regression results, the abovementioned health inequality $\mathrm{CI}$ is decomposed, and the regression coefficient is used as the basis to calculate the elasticity coefficient and each variable's contribution to health inequalities. The results are shown in Table 4. The CI of negative childhood experiences is -0.0192 , which indicates that adults who have experienced fewer negative childhood experiences are healthier. The elasticity coefficient is -0.1189 , indicating that adults with higher income tend to have fewer negative childhood experiences and that they are healthier. Thus, negative childhood experiences have expanded health inequalities, and their contribution accounts for $12.86 \%$.

The contribution of social demographic characteristic variables accounts for almost 41.08\%. Among these variables, the contributions are as follows: hukou, $14.16 \%$; the logarithm of per capita household income, 9.95\%; gender, 8.77\%; education level, 5.34\%; and age, $4.62 \%$. These main factors included household registration type, family income, gender, years of education, and age. The contributions of each variable 
to health inequalities were as follows: hukou, $14.16 \%$; family income, $9.95 \%$ gender, $8.77 \%$; years of education, $5.34 \%$; and age, $4.62 \%$. The contributions of living habits variables to health inequalities were almost $2.32 \%$; among these variables, the contribution of exercise for at least 1 year was $4.90 \%$, and that of drinking alcohol was $-2.60 \%$. The contribution of childhood family characteristics accounts for $12.25 \%$. Among these characteristics, mothers' education levels accounted for $2.70 \%$, fathers' education level accounted for $1.00 \%$, care received from parents accounted for $1.73 \%$, and childhood family economic status accounted for $7.61 \%$.

Table 4 Decomposition of CI

\begin{tabular}{|c|c|c|c|c|c|c|}
\hline Variables & Coefficient & Mean & Elasticity & CI & $\begin{array}{c}\text { CI } \\
\text { contribution }\end{array}$ & $\begin{array}{l}\text { Contribution } \\
\text { rate }(\%)\end{array}$ \\
\hline $\begin{array}{l}\text { Negative childhood } \\
\text { experiences }\end{array}$ & -0.021 & 1.717 & -0.11894 & -0.01918 & 0.00228 & 12.86 \\
\hline Age & -0.001 & 61.439 & -0.22507 & -0.00364 & 0.00082 & 4.62 \\
\hline Gender & -0.039 & 1.501 & -0.20097 & -0.00774 & 0.00155 & 8.77 \\
\hline Hukou & 0.022 & 1.204 & 0.09073 & 0.02768 & 0.00251 & 14.16 \\
\hline Education level & 0.001 & 4.993 & 0.01324 & 0.07147 & 0.00095 & 5.34 \\
\hline Marital status & -0.014 & 0.738 & -0.03825 & 0.0069 & -0.00026 & -1.49 \\
\hline $\begin{array}{l}\text { Logarithm of per } \\
\text { capita household } \\
\text { income }\end{array}$ & 0.001 & 6.983 & 0.0167 & 0.10568 & 0.00177 & 9.95 \\
\hline Family size & -0.002 & 3.096 & -0.01247 & 0.00384 & -0.00005 & -0.27 \\
\hline $\begin{array}{c}\text { Exercise for at least } \\
1 \text { year }\end{array}$ & 0.019 & 0.160 & 0.00977 & 0.08885 & 0.00087 & 4.90 \\
\hline Smoking cigarettes & 0.000 & 0.333 & 0.00008 & 0.04015 & 0.000003 & 0.02 \\
\hline Drinking alcohol & -0.014 & 0.501 & 0.02148 & 0.02148 & -0.00046 & -2.60 \\
\hline $\begin{array}{c}\text { Mother's education } \\
\text { level }\end{array}$ & 0.003 & 0.702 & 0.0086 & 0.05573 & 0.00048 & 2.70 \\
\hline $\begin{array}{c}\text { Father's education } \\
\text { level }\end{array}$ & 0.001 & 2.813 & 0.00601 & 0.02957 & 0.00018 & 1.00 \\
\hline $\begin{array}{c}\text { Care received from } \\
\text { parents }\end{array}$ & 0.004 & 0.665 & 0.02359 & 0.00039 & 0.00001 & 0.05 \\
\hline $\begin{array}{c}\text { Father's family } \\
\text { origin }\end{array}$ & -0.011 & 0.707 & 0.01003 & -0.01487 & -0.00015 & -0.84 \\
\hline
\end{tabular}


Mother's family

origin

Childhood family

economic status

$$
0.002
$$

3.278

0.018

2.494

0.15539

0.00869
1.73

7.61

Next, we explored the mechanism of negative childhood experiences in affecting health inequalities. The impact of negative childhood experiences on health inequalities may result from the different effects of negative childhood experiences on the health of different income groups, which in turn increases health inequalities. We aggregate the income of all respondents and find a median that can divide the respondents into 2 groups. The first group accounts for 50\% of the total income, and the second group accounts for the remaining $50 \%$ of the total income. Furthermore, all respondents in the first group are poorer than those in the second group, through which we can examine the heterogeneity in different income groups (see Table 5). In Model 2 and Model 4, negative childhood experiences have negative effects on both the low-income group $(\beta$ $=-0.0209, \mathrm{p}<0.001)$ and the high-income group $(\beta=-0.0195, \mathrm{p}<0.001)$. By comparing the regression coefficients, we find that negative childhood experiences have a larger negative impact on the low-income group and a smaller negative impact on the highincome group, which leads to an increase in health inequalities.

Table 5 Impact of negative childhood experiences on the health of different income groups

\begin{tabular}{lllll}
\hline \multirow{2}{*}{ Variables } & \multicolumn{2}{l}{ Low-income group } & \multicolumn{2}{l}{ High-income group } \\
& 1 & 2 & 3 & 4 \\
\hline Negative childhood & $-0.0279 * * *$ & $-0.0209 * * *$ & $-0.0236^{* * *}$ & $-0.0195^{* *}$ \\
experiences & $(0.003)$ & $(0.003)$ & $(0.008)$ & $(0.008)$ \\
Other variables & Not controlled & Controlled & Not controlled & Controlled \\
Constant & $0.328^{* * *}$ & $0.383 * * *$ & $0.374 * * *$ & 0.306 \\
R-squared & $(0.006)$ & $(0.037)$ & $(0.014)$ & $(0.232)$ \\
Observations & 0.021 & 0.044 & 0.015 & 0.061 \\
\hline
\end{tabular}


P-values: $* * *<0.001, * *<0.05, *<0.1$

\section{Discussion}

This paper found that negative childhood experiences have a negative impact on an individual's health, and has a greater negative impact on the low-income groups, thus expanding the health inequality of the residents. This means that both the high-income group and the low-income group have lower socioeconomic status, but the negative impact on the low-income group is greater, while the negative impact on the highincome group is smaller [41].

Many studies have demonstrated the relationship between socioeconomic status and individual health [41,42]. Link and Phelan [43] found that socioeconomic status was the most influential factor on an individual's health and life expectancy and that the health of those with higher socioeconomic status was significantly better than the health of those with lower socioeconomic status [44]. Socioeconomic status not only has an impact on people's health but can also have a cumulative effect; that is, people who have long had higher socioeconomic status (or lower status) have better (or worse) health [45].

Education, occupation and income had been thought to be important indicators of socioeconomic status [46]. In health research, education reflects a person's ability to actively access social, psychological and economic resources; occupation reflects a person's social status, sense of responsibility, physical activity status and health risk; income level reflects a person's consumption ability, housing conditions, nutrition status and access to medical and health care resources [47]. Therefore, the unfortunate 
experience of childhood may affect the access to medical service resources and expand health inequality by reducing the residents' education level, professional status and income level.

Negative childhood experiences reduce the possibility of residents' access to education [48]. However, there is a positive correlation between education and health. For example, Winkleby et al. [42] found that education affects people's health through multiple mechanisms and that high levels of education usually translate to better jobs, higher incomes, and greater budget constraint sets [49]. With more economic resources invested in health, such as medical insurance, medical services, health care equipment and facilities, individuals are more likely to have better health [50]. Therefore, negative childhood experiences may change the investment and utilization of medical services of residents through the level of education, and then expand the health inequality.

Negative childhood experiences reduce the possibility of people getting good jobs [7]. Worse jobs increase the possibility of risk exposure in the future, resulting in people in worse jobs facing higher health risks and lacking in health insurance, which makes it difficult to obtain better medical service resources and health care [51]. In China, people in different groups (such as urban workers, urban residents, rural residents, rural migrant workers, etc.) enjoy different medical insurance. The financing level and subsidy standard of the basic medical insurance for urban workers are far higher than that of the basic medical insurance for urban residents and the new rural cooperative medical insurance; the level of medical services utilization (prevalence rate, medical treatment rate, average cost per visit, etc.) of urban employees' basic medical insurance 
participants is higher than that of other two social medical insurance participants[52]. Therefore, negative childhood experiences may affect the utilization of medical services and expand health inequality through occupational status.

Based on the data of the US census, Kitagawa and Hauser [53] found that the health level of low-income people was lower regardless of gender (male, female) or race (white, black). Lei \& Lin [11] got a similar conclusion. He found that income level significantly affected people's health, low-income people have poor health, highincome people have good health, and there was a significant positive correlation between income level and health. Thus, the key factor that the income level can improve the health level is that patients with higher income have stronger ability to pay, then the more medical services are used, the higher the level of improving the health ability. However, negative childhood experiences reduced the income level of residents and further expanded the health inequality.

\section{Conclusion}

Regression results found that negative childhood experiences have a negative impact on an individual's health. Concentration index decomposition found that the contribution of negative childhood experiences to health inequality was $12.86 \%$. Through the mechanism test, negative childhood experiences may lead to lower socioeconomic status (fewer years of schooling, worse occupation and lower income), which was negatively related to medical consumption constraints. Further studies have shown a positive correlation between socioeconomic status and healthcare utilization, which can also cause negative health issues and more likelihood in health inequalities. 
Research on health in adulthood has long emphasized recent risk factors. If the origin of adult diseases can be adequately addressed early in life, both scientific research and medical practice will benefit from this shift [30], as many social problems, including health inequality issues, could be prevented during this early period. The most effective and operative approach to avoid negative childhood issues may be family support aimed at prevention and early intervention, which can help families improve relationships and achieve a balance between work and family responsibilities, thus ensuring family stability and function.

\section{Abbreviations}

CHARLS: China Health and Retirement Longitudinal Study;

CI: Concentration Index.

\section{Declarations}

\section{Ethics approval and consent to participate}

The study was exempt from human subjects' approval (non-identifiable data; not human subjects).

\section{Consent for publication}

Not applicable

\section{Availability of data and materials}

Raw datasets used during the current study are available in the CHARLS repository, [http://charls.pku.edu.cn/index/en.html]

\section{Competing interests}

The authors declare that they have no competing interests.

\section{Funding}


This research was funded by the Humanities and Social Science Fund of Ministry of Education of China (project 19YJCZH221), and the Youth Program of National Natural Science Foundation of China (project 71904079).

\section{Authors' contributions}

LYW and DL designed the study. LYW conducted the primary statistical analysis. DL and XL wrote the initial drafts of the manuscript. All authors read, revised and approved the final manuscript.

\section{Acknowledgments}

We gratefully acknowledge the contribution of National School of Development at Peking University for providing raw data of CHARLS. 


\section{Reference}

1. Levine ME, Cole SW, Weir DR, Crimmins EM. Childhood and later life stressors and increased inflammatory gene expression at older ages. Soc Sci Med, 2015, 130:16-22.

2. Foucault M. Discipline and Punish: The Birth of the Prison. New York: Vintag Books.2012.

3. Akbulut-Yuksel M. War during childhood: The long run effects of warfare on health. J Health Econ,2017,53:117-130.

4. Neelsen S, Stratmann T. Effects of prenatal and early life malnutrition: evidence from the Greek famine." J Health Econ, 2011,30(3):479-488.

5. Almond D. Is the 1918 Influenza Pandemic Over? Long-Term Effects of Inutero influenza Exposure in the Post-1940 U.S. Population. J Polit Econ, 2006, 114(4): $672-712$.

6. Almond D, Currie J. Killing me softly: the fetal origins hypothesis. J Econ Perspect, 2011, 25(3):153-172.

7. Shi ZL, Wu ZM. The long term consequences of early life misfortune on health inequality. J Sociol Study 2018(3):166-194.

8. Humphries KH, Van DE. Income-related health inequality in Canada. Soc Sci Med, 2000, 50(5):663-671.

9. Wagstaff A, Van DE. Overall versus socioeconomic health inequality: a measurement framework and two empirical illustrations. Health Econ, 2004, 13(3):297-301. 
10. Wagstaff A, Van DE. Measuring inequalities in health in the presence of multiplecategory morbidity indicators. Health Econ, 1994, 3(4):281-291.

11. Lei XY, Lin WC. The new rural cooperative medical scheme in rural china: does more coverage mean more service and better health? Health Econ, 2009, 18(S2): 25-46.

12. Wagstaff A,Lindelow M,Gao J,et al. Extending health insurance to the rural population: an impact evaluation of China's new cooperative medical scheme. J Health Econ,2009,28(1):1-19.

13. Wagstaff A, Van DE, Watanabe N. On decomposing the causes of health sector inequalities with an application to malnutrition inequalities in Vietnam. $\mathbf{J}$ Econometrics, 2003, 112(1):207-223.

14. Islam MK, Gerdtham UG, Clarke P, Burström K. Does income-related health inequality change as the population ages? Evidence from Swedish panel data. Health Econ,2010,19(3):334-349

15. Gu H, Kou Y, You H, Xu X, Yang N, Liu J, Xiyan L, Jinghong G, Li X. Measurement and decomposition of income-related inequality in self-rated health among the elderly in China. Int J Equity Health, 2019,18(1):4.

16. Elder HG. The life course as developmental theory. Child Dev,1998, 69(1):1-12.

17. Warren JR. Does growing childhood socioeconomic inequality mean future inequality in adult health? Ann Am Acad Polit SS, 2016, 663(1): 292-330.

18. Benshlomo Y, Kuh D. A life course approach to chronic disease epidemiology: conceptual models, empirical challenges and interdisciplinary perspectives. Int J 
Epidemiol,2002,31(2):285-93.

19. Ma GR. Long-term effects of China's Great Famine to health: Evidence from historical data on CHARLS and county-level mortality. J World Econ, 2011(4):104-123.

20. Hertzman C, Power C. Health and human development: understandings from life course research. Dev Neuropsychol,2003,24(2-3):719-744.

21. Currie J. Healthy, Wealthy, and Wise: Socioeconomic Status, Poor Health in Childhood, and Human Capital Development. J Econ Lit,2009,47(1):87-122.

22. Roseboom TJ, Meulen JHP, Osmond C, Barker DJP, Ravelli ACJ, SchroederTanka JM, Montfrans GA, Michels RPJ, Bleker OP. Coronary heart disease after prenatal exposure to the Dutch famine,1944-45. Heart, 2000,84(6):595-598.

23. Grantham-Mcgregor SM, Powell CA, Walker SP, Himes JH. Nutritional supplementation, psychosocial stimulation, and growth of stunted children: the Jamaican study. Am J Clin Nutr, 1991, 54(4):642-648.

24. Maluccio JA, Hoddinott J, Behrman JR, Martorell R, Quisumbing AR, Stein AD. The impact of improving nutrition during early childhood on education among Guatemalan adults. Econ J, 2009,119(537):734-763.

25. Victora CG, Adair L, Fall C, Hallal PC, Martorell R, Richter L, Sachdev HS. Maternal andchild undernutrition. Consequences for adult health and human capital. Lancet, 2008, 371(9609):340-357.

26. Stanner SA, Bulmer K, Andrès C, Lantseva OE,Borodina V, Poteen VV, Yudkin JS. Does malnutrition in utero determine diabetes and coronary heart disease in 
adulthood? Results from the Leningrad siege study, a cross sectional study. Brit Med J,1997, 315(7119):1342-1348.

27. Chen Y, Zhou LA. The Long-term health and economic consequences of the 1959-1961 famine in China. J Health Econ, 2007, 26(4):659-681.

28. Bleakley H. Malaria Eradication in the Americas: A Retrospective Analysis of Childhood Exposure. Am Econ J-Appl Econ,2010,2(2):1-45.

29. Hoynes HW, Schanzenbach DW, Almond DA. Long Run Impacts of Childhood Access to the Safety Net. Am Econ Rev, 2012, 106(4):903-934.

30. Ferraro KF, Schafer MH, Wilkinson LR. Childhood disadvantage and health problems in middle and later life. Am Sociol Rev, 2015, 81(1):107-133.

31. Friedman EM, Montez JK, Sheehan CM, Guenewald TL, Seeman TE. Childhood adversities and adult cardiometabolic health: does the quantity, timing, and type of adversity matter? J Aging Health, 2015, 27(8):1311-38.

32. Montez JK, Hayward MD. Cumulative childhood adversity, educational attainment, and active life expectancy among U.S. adults. Demography, 2014,51(2):413-435.

33. Pearlin LI, Schieman S, Fazio EM, Meersman SC. Stress, health, and the life course: some conceptual perspectives. J Health Soc Behav, 2005, 46(2):205-219.

34. Lloyd TDA. Lifetime Traumas and Mental Health: The Significance of Cumulative Adversity. J Health Soc Behav, 1995, 36(4):360-376.

35. Idler EL, Kasl SV. Self-ratings of health: Do they also predict change in functional ability?. J Gerontol,1995,50(6):S344. 
36. Heidrich J, Liese AD, Lowel H, Kell U. Self-rated health and its relation to allcause and cardiovascular mortality in southern Germany. Results from the MONICA Augsburg cohortstudy 1984-1995. Ann Epidemiol, 2002, 12(5):338345.

37. Van DE, Gerdtham UG. Does inequality in self-assessed health predict inequality in survival by income? Evidence from Swedish data.[J]. Soc Sci Med,2010,57(9):1621-1629.

38. Schafer MH, Ferraro KF, Mustillo SA. Children of misfortune: early adversity and cumulative inequality in perceived life trajectories. Am J Sociol, 2011, 116(4):1053-1091.

39. Engel GL. The need for a new medical model: a challenge for biomedicine. Science. 1977, 196(4286):129-136.

40. Frijters P, Ulker A. Robustness in health research: Do differences in health measures, techniques, and time frame matter?. J Health Econ, 2008, 27(6):16261644.

41. Schafer MH, Wilkinson LR, Ferraro KF. Childhood (Mis)fortune, educational attainment, and adult health: contingent benefits of a college degree?. Soc Forces, 2013,91(3):1007-1034.

42. Winkleby MA, Fortmann SP, Barrett DC. Social class disparities in risk factors for disease: Eight-year prevalence patterns by level of education. Prev Med, 1990, 19(1):1-12.

43. Link BG, Phelan JC. McKeown and the idea that social conditions are 
fundamental causes of disease. Am J Public Health, 2002, 92(5):730-732.

44. Mackenbach JP, Stirbu I, Roskam AJR, Schaap MM, Menvielle G, Leinsalu M, Kunst AE.Socioeconomic inequalities in health in 22 European countries. New Engl J Med, 2008, 359(12): 1290-1291.

45. Heraclides A, Brunner E. Social mobility and social accumulation across the life course inrelation to adult overweight and obesity: the white hall II study. J

Epidemiol Commun H, 2010, 64(8):714-719.

46. Blau PM, Duncan OD. The American occupational structure. Am J Sociol, 1967, 33(2):296.

47. Wang FQ.Socioeconomic status, lifestyle and health inequality. Chinese J Sociol, 2012, 32(2):125-143.

48. Currie J. Inequality at Birth: Some Causes and Consequences. Am Econ Rev, 2011, 101(3):1-22.

49. Moen ER. Education, ranking, and competition for jobs. J Labor Econ, 2000, 17(4):694-723.

50. Cutler DM, Lleras-Muney A. Understanding differences in health behaviors by education. J Health Econ, 2010, 29(1):1-28.

51. Ferrie JE, Shipley MJ, Stansfeld SA, Smith GD, Marmot M. Future uncertainty and socioeconomic inequalities in health: the Whitehall II study. Soc Sci Med, 2003, 57(4):637-646.

52. Huang X. Whether the income-related health inequality has increased. Stat Res, 2012,(6):51-59. 
53. Kitagawa EM, Hauser PM. Differential mortality in the United States: a study in socioeconomic epidemiology. Cambridge, Massachusetts, 1973, Harvard University Press. 